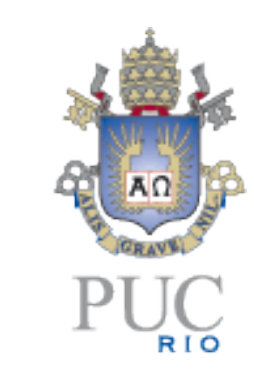

Pontifícia Universidade Católica do Rio de Janeiro

\title{
Abandono de Carrinhos em E-Commerces no Brasil \\ Caso Inti
}

\author{
Elizabete de Souza Menezes \\ Trabalho de Conclusão de Curso
}

Centro de CiênCIAS Sociais - CCS

DEPARTAMENTO DE ADMINISTRAÇÃO Graduação em Administração de Empresas 




Elizabete de Souza Menezes

\section{Abandono de Carrinhos em E-commerces no Brasil \\ Caso Inti}

Trabalho de Conclusão de Curso

Trabalho de Conclusão de Curso, apresentado ao programa de graduação em Administração da PUC-Rio como requisito parcial para a obtenção do título de graduação em Administração.

Orientador(a) : VIVIAN PEUKER SARDON STEINHAUSER

Rio de Janeiro, Novembro de 2019. 
"Os tempos são líquidos porque, assim como a água, tudo muda muito rapidamente. Na sociedade contemporânea, nada é feito para durar." (Zygmunt Bauman) 


\section{Agradecimentos}

Dedico o presente trabalho aos meus pais, Heloiza Helena e Paulo Cesar, meus maiores exemplos na vida em todos os parâmetros. Agradeço pela paciência e compreensão nesses quatro anos de jornada universitária. Agradeço também aos meus amigos e companheiros de PUC-Rio que foram importantes incentivadores e tornaram a universidade uma experiência única.

Agradeço imensamente à minha orientadora Vivian Steinhäuser, que com muita atenção e paciência, conseguiu me guiar nestes meses de produção, sem ela, este trabalho não seria possível.

E por fim, um especial agradecimento a Rebecca Lima, Giovanna Lorenzetti e equipe, por terem me dado a oportunidade de estudar o caso Inti durante todo esse período, além de toda a atenção e insights que com certeza estão traduzidos neste texto. 


\section{Resumo}

de Souza Menezes, Elizabete. Abandono de Carrinhos em E-commerces no Brasil. Caso Inti. Rio de Janeiro, 2019. 37p. Trabalho de Conclusão de Curso - Departamento de Administração. Pontifícia Universidade Católica do Rio de Janeiro.

O presente estudo visa investigar as razões e impactos do expressivo número de carrinhos abandonados em e-commerces brasileiros, a partir do caso da empresa Inti Brazilian Beachwear, e-commerce de moda praia. Para isso, foram realizadas entrevistas com uma seleção de clientes da marca e potenciais clientes que abandonaram carrinhos no site durante o período da pesquisa, além de uma análise em uma amostra de carrinhos abandonados e de pedidos finalizados. A partir das respostas das entrevistadas e das observações nos canais de comunicação da marca, foram elaboradas análises e, posteriormente, recomendações à Inti, objetivando impulsionar as vendas e reduzir o abandono de carrinhos no site.

Palavras-chave: Moda, beachwear, resortwear, Inti, E-commerce, marketing digital, carrinhos abandonados, venda online.

\footnotetext{
Abstract

de Souza Menezes, Elizabete. Abandonment of Carts in E-commerces in Brazil. Inti Case. Rio de Janeiro, 2019. 37 pages. Course Completion Work - Administration Department. Pontifical Catholic University of Rio de Janeiro.
}

This study aims to investigate the reasons and impacts of the number of abandoned carts in Brazilian e-commerces, based on the case of Inti Brazilian Beachwear, a beachwear e-commerce. For this objective, interviews were conducted with a selection of customers and potential customers who abandoned carts on the site during the survey period, as well as an analysis of an abandoned carts sample and completed orders. From the answers of the interviews and brand communication channels, analyzes were elaborated and later applied to Inti, aiming the impulse of sales and reduction or abandonment of carts on the website.

Keywords: Fashion, beachwear, resortwear, Inti, E-commerce, digital marketing, abandoned carts, online sale. 



\section{Sumário}

$\begin{array}{ll}\text { 1. Introdução } & 10\end{array}$

$\begin{array}{ll}1.1 \mathrm{~A} \text { Inti } & 10\end{array}$

$\begin{array}{ll}1.2 & \text { O Abandono de Carrinhos } \\ \end{array}$

$\begin{array}{ll}1.3 \text { Objetivo da Pesquisa } & 12\end{array}$

1.4 Delimitação 12

$\begin{array}{ll}1.5 \text { Relevância } & 12\end{array}$

2. Contextualização 13

$\begin{array}{ll}2.1 \text { O Mercado de Moda Praia } & 13\end{array}$

2.2 O Comportamento do Consumidor Brasileiro Online 14

$\begin{array}{ll}\text { 2.3 Mix de Marketing da Inti } & 16\end{array}$

$\begin{array}{ll}\text { 2.3.1 Produto } & 16\end{array}$

$\begin{array}{ll}\text { 2.3.2 Preço } & 17\end{array}$

$\begin{array}{ll}\text { 2.3.3 Praça } & 18\end{array}$

$\begin{array}{ll}\text { 2.3.4 Promoção } & 19\end{array}$

$\begin{array}{ll}\text { 3. Etapas da Pesquisa } & 21\end{array}$

3.1 Etapa 1

3.2. Etapa 2

$\begin{array}{ll}3.3 \text { Etapa } 3 & 21\end{array}$

3.4 Etapa $4 \quad 22$

$\begin{array}{ll}3.5 \text { Etapa } 5 & 22\end{array}$

3.6 Etapa $6 \quad 22$

4. Entrevistas 23

4.1 Relação com a Marca 23

4.2 Características e Incentivos de Consumo 24

$\begin{array}{ll}\text { 4.3 Abandono de Carrinhos } & 25\end{array}$

5. Análise dos Carrinhos 27 
$\begin{array}{ll}\text { 5.1 Carrinhos de Venda } & 27\end{array}$

$\begin{array}{ll}\text { 5.2 Carrinhos Abandonados } & 28\end{array}$

6. Recomendações 29

$\begin{array}{ll}\text { 6.1 Relacionamento com as Clientes } & 29\end{array}$

$\begin{array}{ll}\text { 6.2 Ferramentas no Site } & 30\end{array}$

$\begin{array}{ll}6.3 \text { Frete } & 30\end{array}$

6.4 Recomendações Finais 32

7. Conclusão e Considerações Finais 33

8. Referências Bibliográficas 34

$\begin{array}{ll}\text { Anexo } 1 & 36\end{array}$

$\begin{array}{ll}\text { Anexo } 2 & 37\end{array}$ 


\section{Lista de Tabelas}

Tabela 1: Tabela de Fretes Flash Courier 28

Tabela 2: Comparação Frete Rio 31

Tabela 3: Comparação Frete São Paulo 31 


\section{Lista de Figuras}

$\begin{array}{lr}\text { Figura 1: Inti Swim } & 10\end{array}$

$\begin{array}{ll}\text { Figura 2: Time line Inti } & 11\end{array}$

Figura 3: Comparação Bodies Inti x Haight x Esc. 14

$\begin{array}{ll}\text { Figura 4: Abandono de carrinhos por categoria } & 15\end{array}$

Figura 5: Principais razões de abandonos de carrinhos nos EUA em nov/2018 16

Figura 6: Conjunto Lume - Romana Novais 17

$\begin{array}{ll}\text { Figura 7: Inauguração Inti Store } & 18\end{array}$

$\begin{array}{lr}\text { Figura 8: Anúncios Inti Swim } & 19\end{array}$

$\begin{array}{ll}\text { Figura 9: Inti Girls } & 20\end{array}$

Figura 10: Vendas por tamanho em intiswim.com 27 


\section{Introdução}

Este capítulo trará uma contextualização sobre a marca analisada e as características do mercado de e-commerce brasileiro. Além disso, será apresentado o objetivo, a delimitação e a relevância da pesquisa.

\section{$1.1 \mathrm{~A}$ Inti}

A Inti é um e-commerce de roupas resort e moda praia, situado no Rio de Janeiro, mas com atuação a nacional via e-commerce. A empresa existe há pouco mais de 2 anos, e vem ganhando notoriedade no espaço digital, com mais de 55 mil seguidores no Instagram e atingindo até 25 mil acessos mensais no site. Além disso, a Inti também vende no atacado e está presente em mais de 50 lojas pelo Brasil, nos Estados Unidos e na Europa. A marca foi criada por Giovanna Lorenzetti e Rebecca Lima, que, em entrevista para elaboração do projeto, contaram um pouco sobre o conceito e objetivos da marca.

A marca de beach e resortwear de luxo carioca nasceu da necessidade e da oportunidade identificada no mercado de moda praia brasileiro. Fruto de diversas viagens e do encantamento pelos mistérios Inca, as duas encontraram o nome Inti para representar a marca que buscaria traduzir a paixão pelo minimalismo e a contemporaneidade da arquitetura. Inti é uma palavra derivada da língua Quechua e significa "Deus do Sol",

A assimetria, traços e recortes estão sempre presentes nas modelagens versáteis, que, segundo as gestoras, vão "além mar". Os modelos são desenvolvidos com um design atemporal e peças únicas, que transitam entre a ousadia e a elegância (figura 1). Para a próxima coleção, a marca buscará se aproximar mais ainda da moda casual e, com mais investimento interno, estará oficialmente no varejo internacional online.


Figura 1: Inti Swim.

Fonte: Instagram (@inti_swim) 
As gestoras e fundadoras buscam definir a mulher Inti como ousada e confiante; moderna e atuante; e que valoriza experiências singulares, viagens inesquecíveis e está sempre presente nos melhores hotspots nacionais e internacionais. As maiores inspirações das duas amigas e sócias são a arquitetura, a arte e a autenticidade da moda. Elas acreditam que, com propósito, todos os sonhos podem ser alcançados. Abaixo, segue a timeline da marca (figura 2), cedido de material interno da empresa.

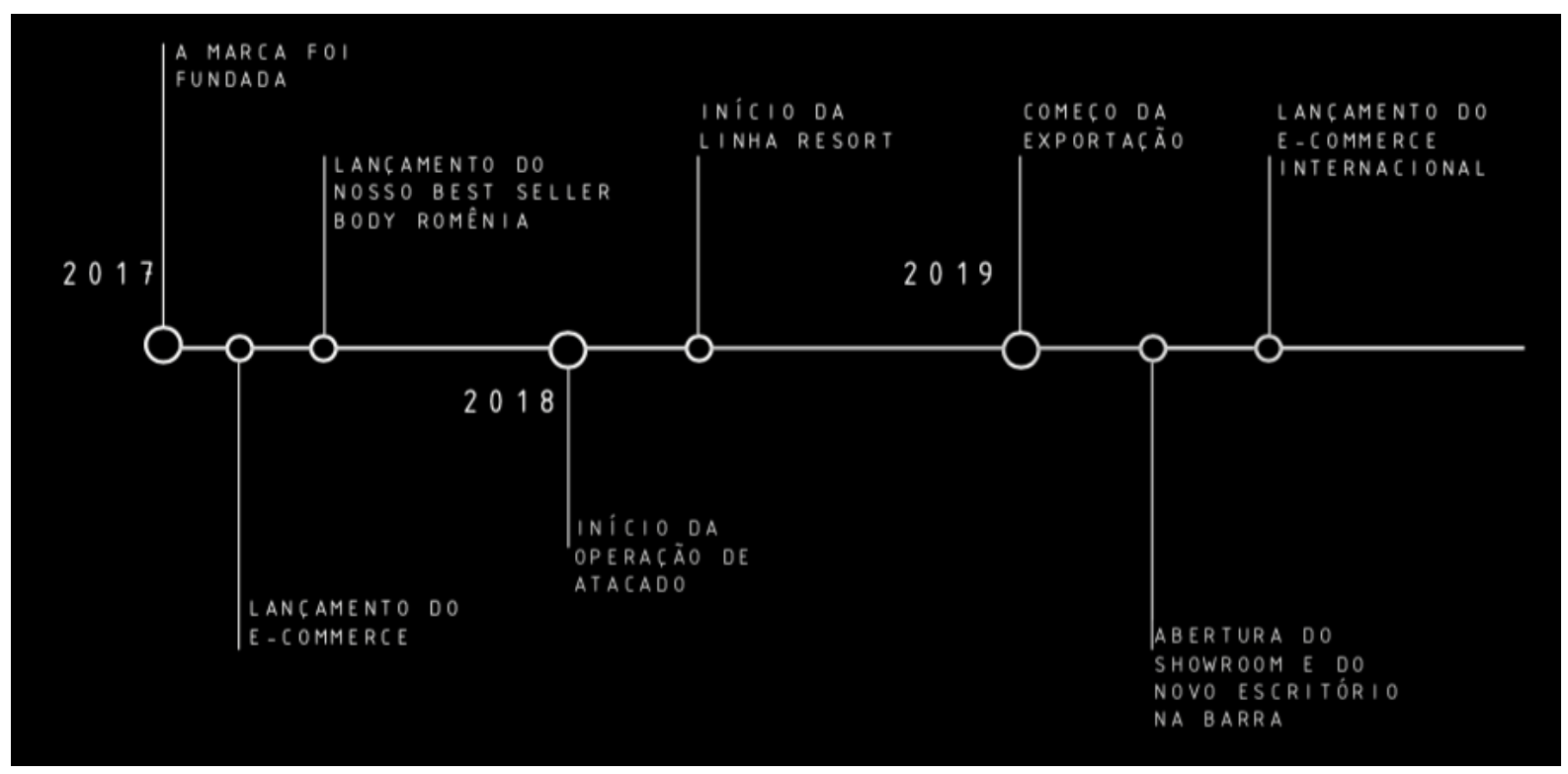

Figura 2: Time line Inti.

Fonte: Arquivos Inti (2019).

\subsection{O Abandono de Carrinhos}

A empresa triplicou de faturamento em 2019 em relação ao mesmo período em 2018, devido ao avanço da produção, reconhecimento da marca e aumento nos investimentos internos. Junto ao aumento do faturamento, houve um aumento no investimento em marketing digital via anúncios em redes sociais, como Facebook e Instagram.

O investimento nesse formato de anúncio gera grandes resultados quando bem mensurados, e uma das análises que pode ser feita para garantir que o público certo esteja sendo atingido nas redes é o número de adições ao carrinho feitos pelos usuários do site. $A$ Inti tem um grande problema com carrinhos abandonados, e esse trabalho tratará exatamente deste tema. 


\subsection{Objetivo da Pesquisa}

O principal objetivo do trabalho é identificar os possíveis motivos de um número tão alto em abandono de carrinhos, a partir da análise do comportamento das clientes e potenciais clientes em relação à marca. Para isso, serão estudados os seguintes tópicos, que configuram como objetivos específicos:

- Identificar as características em comum mais presentes entre as clientes.

- Analisar as diferenças entre carrinhos abandonados e finalizados: valor, repetição e tamanhos de produto adicionados ao carrinho (comparação entre peças), valor do frete e localidade de residência.

- Identificar motivos de abandono de carrinhos entre clientes antigas da marca.

- Identificar as principais motivações de compra das clientes.

- Identificar os principais motivos de abandono de carrinho.

\subsection{Delimitação}

Para a delimitação da pesquisa foi utilizado como objeto de estudo, o site da empresa (www.intiswim.com) e os dados e informações das clientes da marca obtidos através do CRM da Inti. A pesquisa foi feita entre os dias 15 de outubro de 2019 e 18 de outubro de 2019. Além disso, a pesquisa com as clientes e potenciais clientes foi feita via WhatsApp da própria Inti, identificando que se tratava de uma pesquisa universitária.

\subsection{Relevância}

Este trabalho trouxe informações sobre o comportamento do consumidor brasileiro no mercado digital, principalmente do público feminino de alto poder aquisitivo no mercado de moda. Tal segmento carece de informações aprofundadas sobre opiniões e comportamentos dos compradores, logo, o estudo pode ser utilizado por outras marcas para entender as características relevantes de comportamentos semelhantes de seus consumidores, principalmente quanto ao atendimento aos clientes. Também foi útil para a marca, que poderá usar o estudo como base para seu crescimento online e otimização do investimento em anúncios digitais, visto que após a análise, algumas sugestões aplicáveis foram sugeridas, visando a redução do abandono e a conversão dos abandonos em vendas. Além disso, revelou informações realistas sobre a razão do abandono de carrinhos por pessoas habituadas a fazerem compras online, o que cria uma base de outros questionamentos importantes para pesquisas futuras, como por exemplo, os fatores de segurança e usabilidade do e-commerce que influenciam no comportamento de compra online. 


\section{Contextualização}

Neste capítulo, serão apresentados dados do mercado em que a empresa está inserida, que servirão de base para a análise. Também, será apresentado, com mais detalhes, o caso especial de abandono de carrinhos pelos consumidores brasileiros. $\mathrm{E}$ por fim, detalhes sobre o produto, preço, praça de atuação e promoção da Inti. O capítulo está dividido entre o mercado de moda praia, o comportamento do consumidor online no Brasil e 4 P's na Inti.

\subsection{O Mercado de Moda Praia}

Segundo dados do Comitê da Cadeia Produtiva da Indústria Têxtil, Confecção e Vestuário da Fiesp (COMTEXTIL, 2018), em 2017, as pequenas e microempresas foram responsáveis por $97 \%$ da produção e $66 \%$ dos empregos no setor de Moda Praia. Nos últimos 5 anos, o setor sofreu uma queda considerável, com o fechamento de $34 \%$ das empresas e $17 \%$ de demissões entre as pequenas e médias. Foi exatamente nesse momento que surgiu a Inti, com uma produção inicial pequena e visando um público de elite no sudeste do país.

Ainda segundo dados da Fiesp (2018), a região Sudeste concentra o mercado consumidor e a produção de moda praia de varejo e atacado do Brasil. No Sudeste se concentra $48,1 \%$ da produção nacional, seguido do Sul, com $30,6 \%$, e do Nordeste, com $16,7 \%$. Centro-Oeste e Norte, juntos, responderam por $4,4 \%$ da produção total do ano de 2017. Vale ressaltar ainda o potencial do Nordeste como mercado de distribuição.

$\mathrm{Na}$ região sudeste, a Inti compete diretamente com algumas marcas jovens em ascensão, como a Haight Clothing e a Esc Brand, que têm a mesma proposta de produtos e preços similares (figura 3). A estratégia online das marcas é parecida, sendo a Inti um pouco mais agressiva em volume e variedade nos anúncios veiculados, conforme análise das próprias redes sociais das marcas. 

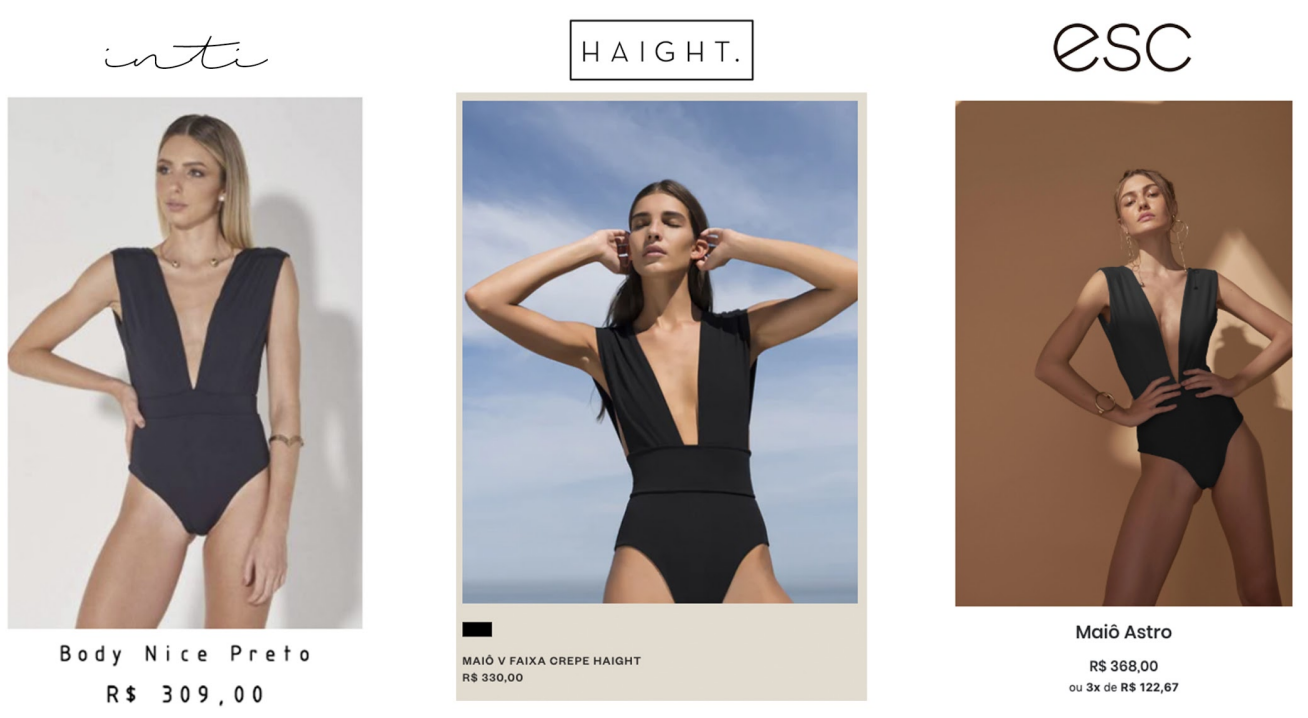

Figura 3: Comparação Bodies Inti x Haight x Esc.

Fonte: Elaborada pela autora.

\subsection{O Comportamento do Consumidor Brasileiro Online}

No século XXI, estar bem posicionado digitalmente deixou de ser uma opção, tanto para profissionais, quanto para marcas (MANGOLD \& FAULDS, 2009). E o consumidor está de acordo com esse novo modo de conhecer as marcas (GOH; HENG \& LIN, 2013).

No Brasil, o contato via rede social é ainda mais importante: 140 milhões de brasileiros estão conectados nas mídias sociais digitais, o que significa que $66 \%$ da população nacional acessa este tipo de conteúdo diariamente (WE ARE SOCIAL, 2019). Além disso, os brasileiros passam mais tempo online que o resto do mundo, em média três horas e 34 minutos por dia, o que é superior à média mundial diária de duas horas e 16 minutos (WE ARE SOCIAL, 2019), esse tempo, é passado principalmente em sites de notíciais, ecommerces e redes sociais.

Em adição, de acordo com números da Forrester Research (2019), a média mundial de abandono de carrinhos é de $50 \%$. Mas, no Brasil, esse número é ainda mais impressionante, girando em torno de $82 \%$ na média geral e $83 \%$ no setor de Moda e Acessórios (figura 4), conforme aponta pesquisa E-commerce Radar, feita pela Neo Atlas (2019). 


\section{ABANDONO DE CARRINHO POR CATEGORIA}

\section{NEOATLAS}

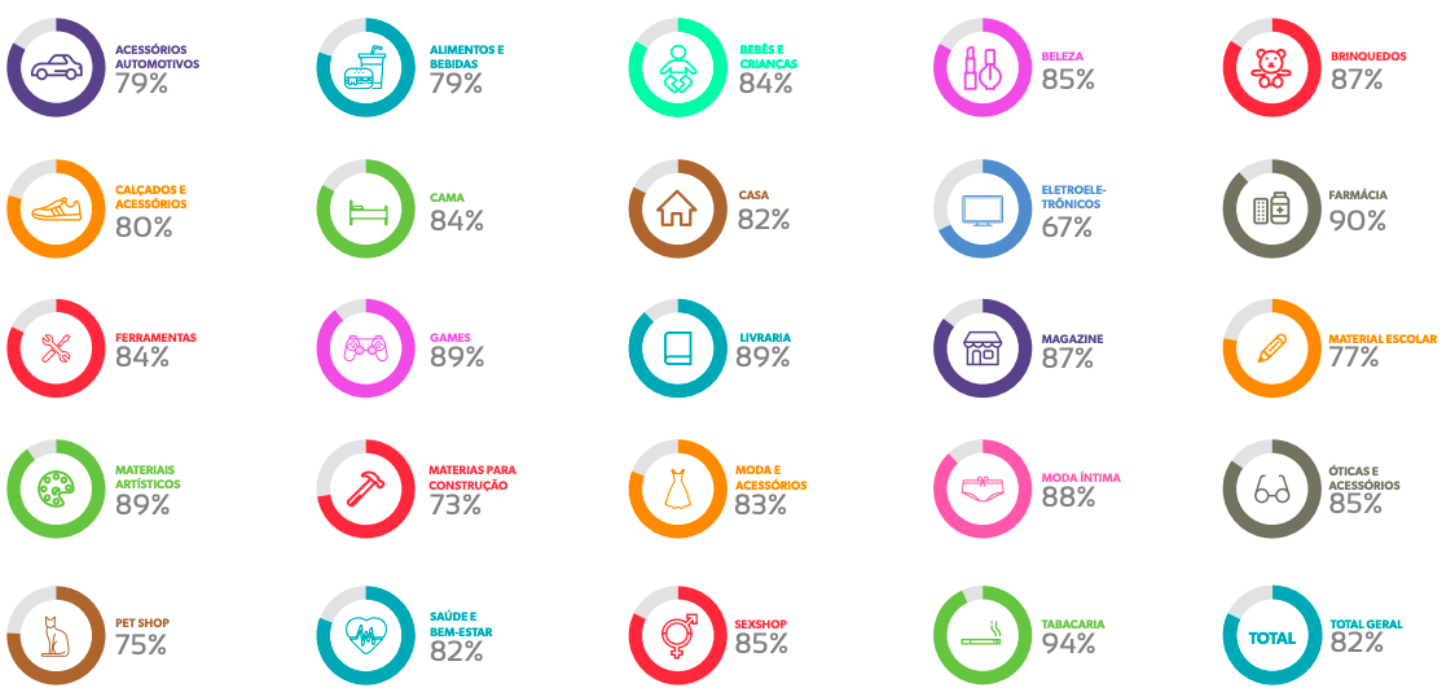

Figura 4: Abandono de carrinhos por categorias.

Fonte: Ecommerce Radar, Neo Atlas, 2019.

Esse cálculo é feito com a relação entre "adições ao carrinho" e "checkouts finalizados". Isso significa que $83 \%$ das pessoas que iniciam uma compra não finalizam o pedido. Na Inti, esses números são ainda mais alarmantes, quando analisamos a quantidade de carrinhos abandonados em comparação com a finalização de compra no site. Considerando os anúncios online, encontramos uma taxa de $92 \%$ de abandono de carrinhos. Ou seja, de todo o tráfego pago investido em anúncios digitais que escolhe uma peça no site, apenas $8 \%$ é convertido, efetivamente, em venda.

Em adição, segundo o portal de dados alemão de estatísticas, Statista (2018), 63\% dos entrevistados em uma pesquisa sobre os motivos de abandono de carrinhos em sites americanos no mês da Black Friday do ano passado, disseram que deixam de finalizar uma compra pelo alto custo de frete. 
Primary reason for digital shoppers in the United States to abandon their carts as of November 2018

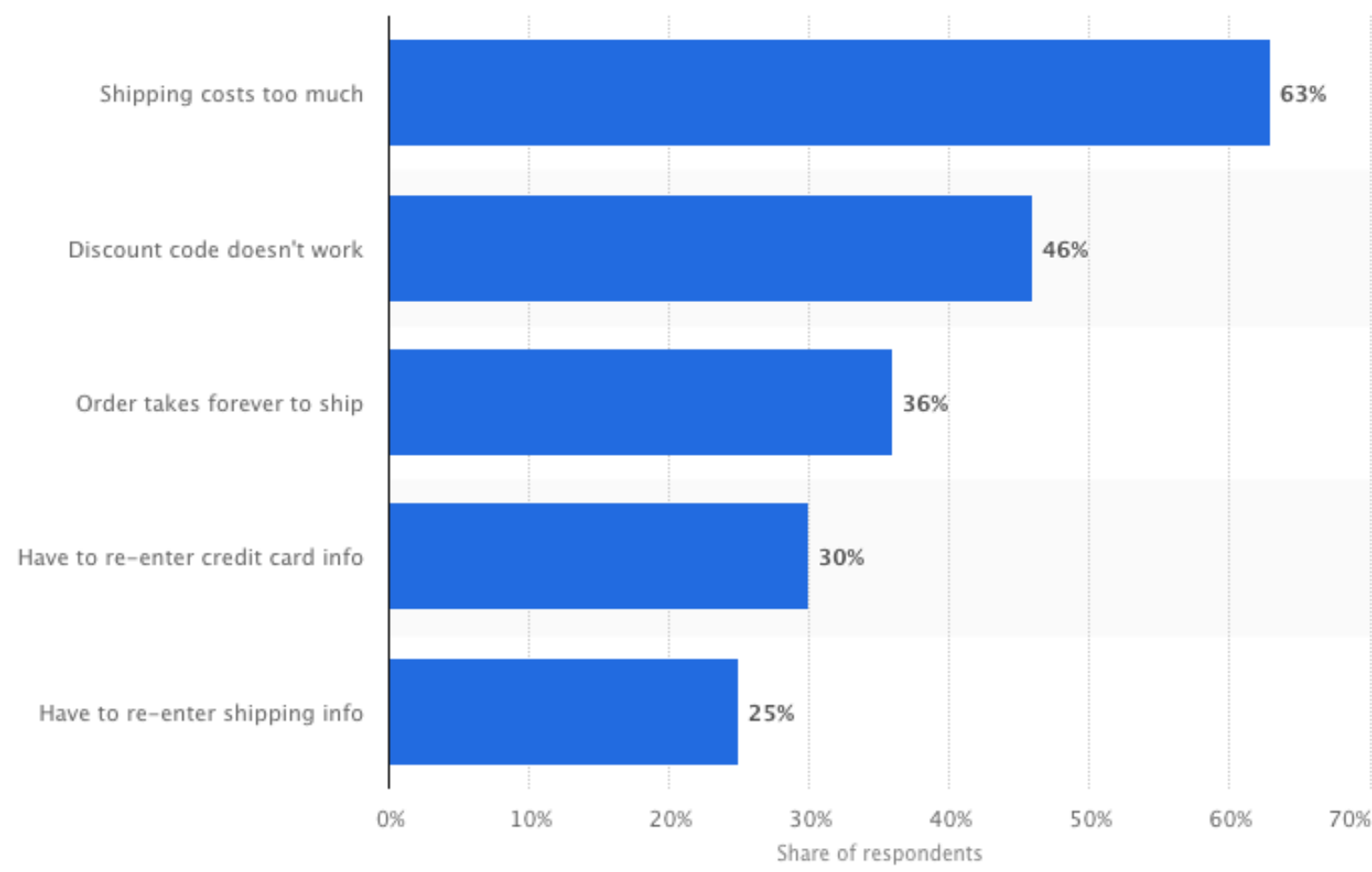

Figura 5: Principais razões de abandonos de carrinhos nos EUA em nov/2018.

Fonte: Statista, 2019.

\subsection{Mix de Marketing da Inti}

Para maior contextualização sobre o universo da marca dentro das perspectivas do estudo, foi feita uma análise referente aos 4 elementos do composto de marketing: produto, preço, praça e promoção, sob a ótica da Inti.

\subsubsection{Produto}

A Inti começou sua atuação há pouco mais de 2 anos, com foco no setor de moda praia. Porém com o desenvolvimento das coleções, os produtos diferenciados e exclusivos acabaram levando a marca para um público que se interessou cada vez mais por peças que fossem além da praia. Em pouco tempo, os biquínis e bodies se associaram a saídas de praia, pantalonas, vestidos e até macacões, cada vez mais sofisticados. A marca aposta em peças versáteis para serem usadas em diversas ocasiões. Hoje em dia, há uma grande busca de produtos para looks de festas, e até mesmo ensaios de pré-casamento. Os produtos são lançados em três coleções ao ano: Inverno, Verão e Alto Verão. Eles são desenvolvidos 
internamente e a produção é feita em confecções parceiras, com acompanhamento próximo da equipe da Inti.

\subsubsection{Preço}

Os preços dos produtos atualmente variam de $\mathrm{R} \$ 299,00$, com bodies e biquínis, até $\mathrm{R} \$ 849,00$, com produtos principalmente da linha festas. O preço é competitivo em relação aos principais concorrentes, como mostrado na figura 3 .

Quando se trata de produtos diferenciados e únicos, a Inti pratica preços um pouco mais altos, como no caso do "Conjunto Lume". Este é uma combinação de body e saia, que foi usada no réveillon de 2019 pela influenciadora Romana Novais (figura 6). A peça foi falada por revistas online como a vix.com, além de muito comentada nas redes sociais na época, o que trouxe muita visibilidade para a marca. Pela exclusividade e sucesso prévio, o modelo está sendo repetido na coleção de alto verão de 2020, com um preço mais alto.


Figura 6: Conjunto Lume, Romana Novais.

Fonte: Instagram (@romananovais) 


\subsubsection{Praça}

A Inti lançou seu e-commerce em 2017, e desde então, este vem sendo seu maior canal de vendas, tanto para o Rio de Janeiro quanto para todo o Brasil. Mas além disso, em meados de 2019, a marca lançou seu primeiro ponto físico, um Showroom/Loja (figura 7) feito para receber as clientes cariocas de forma mais íntima e especial. Além de eventualmente apresentar a coleção presencialmente a lojistas. O espaço fica na Barra da Tijuca e funciona lado a lado com o escritório e o estoque da empresa. É interessante ressaltar que, frequentemente, clientes de outros estados a passeio no Rio de Janeiro, aproveitam a oportunidade para conhecer as peças pessoalmente em uma visita ao showroom.

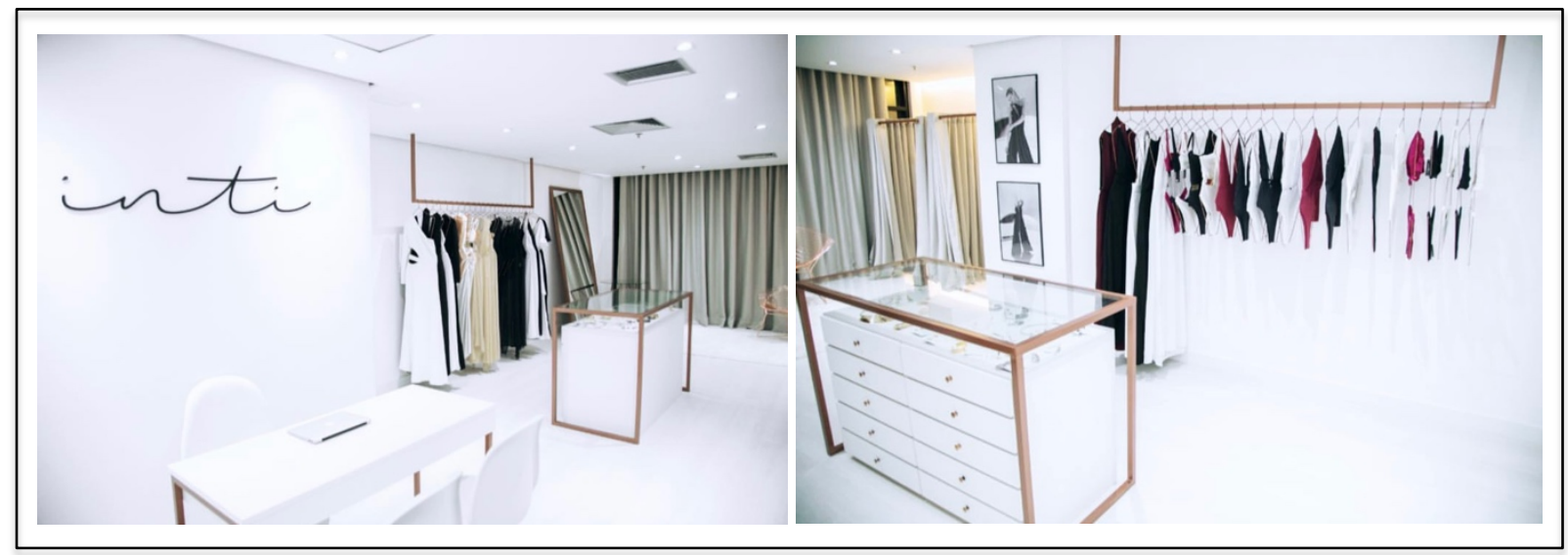

Figura 7: Inauguração Inti Store.

Fonte: Arquivos Inti (2019).

Em adição, a Inti atua com venda em atacado para lojas multimarcas, atualmente existem mais de 50 clientes vendendo Inti no Brasil, além de lojas nos Estados Unidos, Itália, Peru, Líbano e na Turquia. Até dezembro de 2019, a empresa estará atuando no varejo internacional via E-commerce, com foco nos Estados Unidos e na Espanha, onde já há um número considerável de acessos no site e pedidos via Instagram. A distribuição das vendas online é feita via correios e transportadora (Flash Courier) e também há a possibilidade de retirar compras feitas no site, no showroom. 


\subsubsection{Promoção}

A promoção da marca e dos produtos é feita de forma bastante visual e intensa no Instagram, Site, E-mail e WhatsApp. Além disso, também há as campanhas patrocinadas no Instagram e Facebook, que são veiculadas com imagens e vídeos (figura 8).

O público consome os conteúdos nesses formatos de forma bastante positiva. As artes gráficas, vídeos e fotos conversam de forma harmoniosa entre os banners do site, stories do Instagram, comunicação via E-mail Marketing e até na linguagem usada no atendimento via WhatsApp.

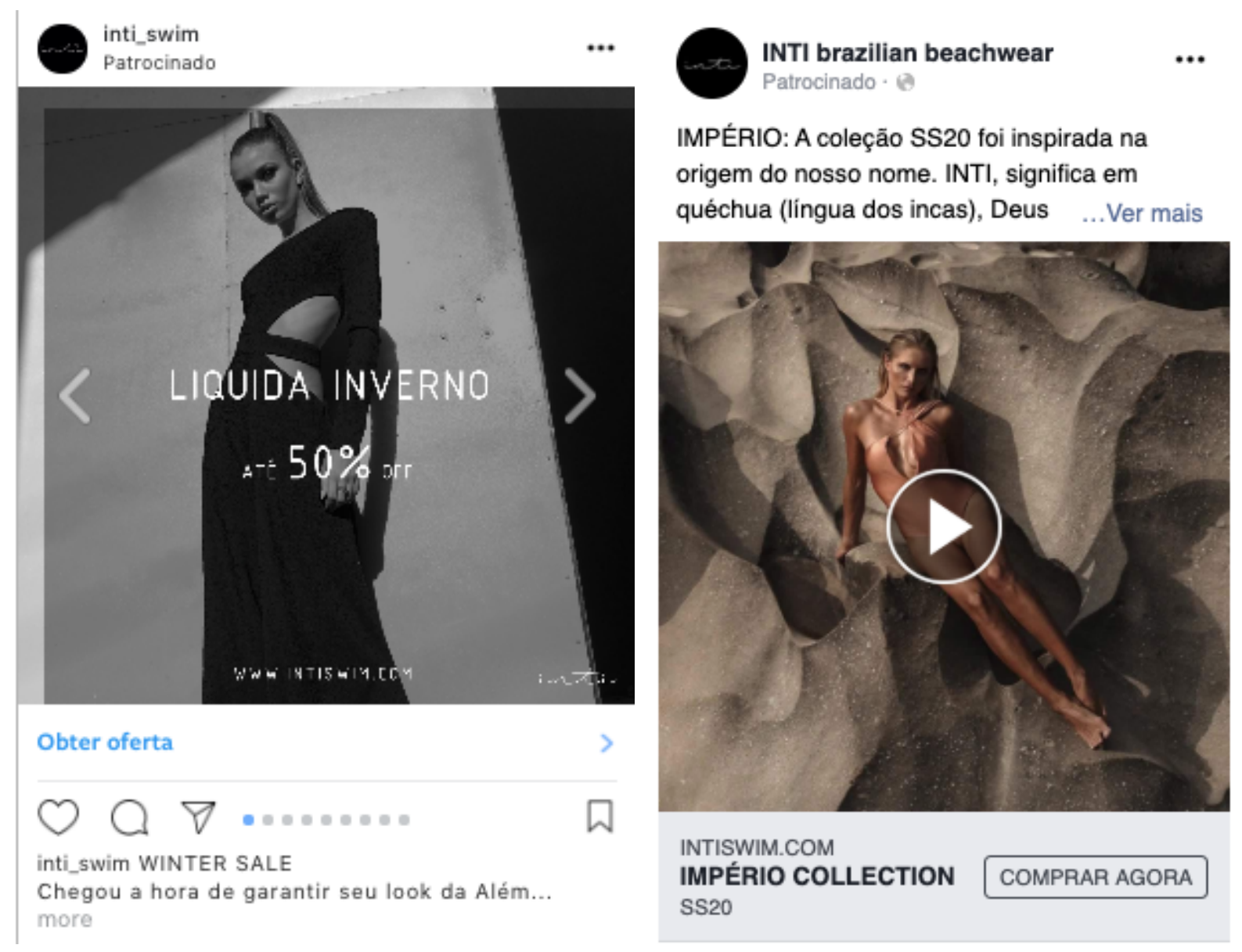

\section{Figura 8: Anúncios Inti Swim}

Fonte: Arquivos Inti (2019).

A ideia, segundo as gestoras, é cada vez mais unificar as formas de comunicação, para que a promoção da marca seja sempre a mais singular e exclusiva possível. 
Além disso, a marca também busca estar presente em produções de atrizes, como Paolla Oliveira e Isis Valverde, e influenciadoras, como Gabriela Pugliesi e Mariana Gonzalez (figura 9), além de ser pauta de editoriais de revistas frequentemente.

\section{INT I GIRLS}

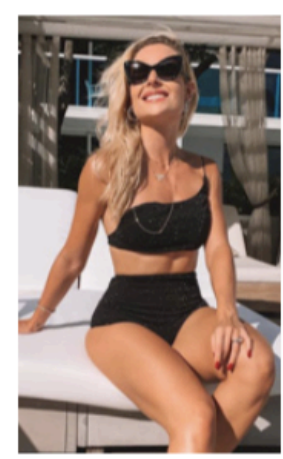

LAYLAMONTEIRO

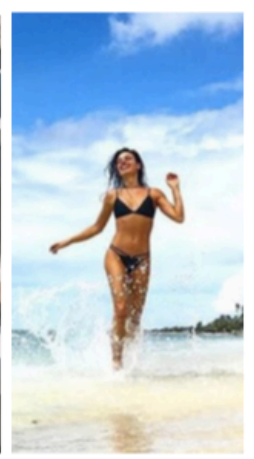

ISIS VALVERDE

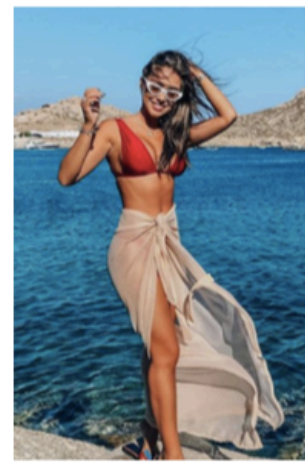

GABRIELLA LENZI

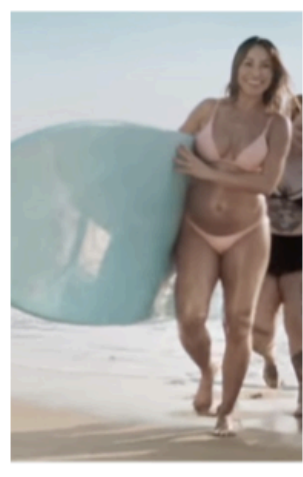

SABRINA SATO

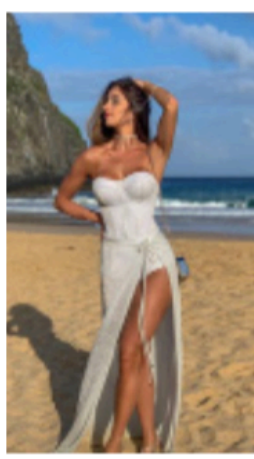

ROMANANOVAIS



PAOLLA OLIVEIRA

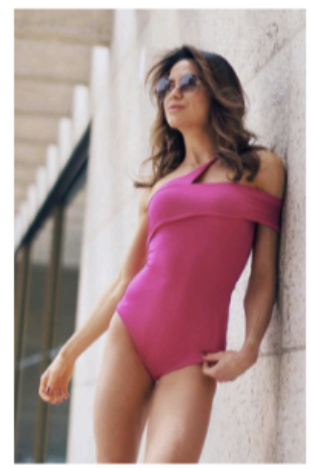

JUJU NORREMOSE

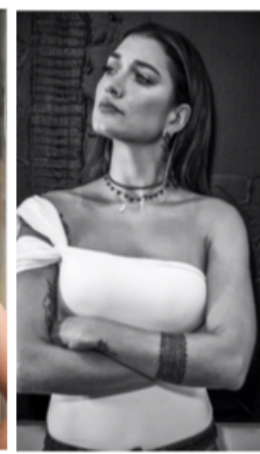

GABRIELA PUGLIESI

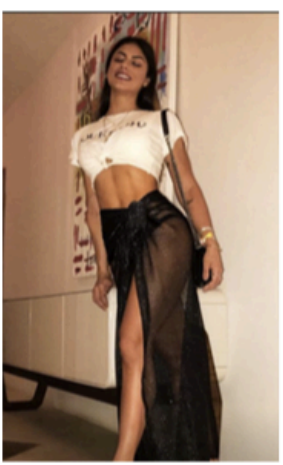

MARIANA GONZALEZ

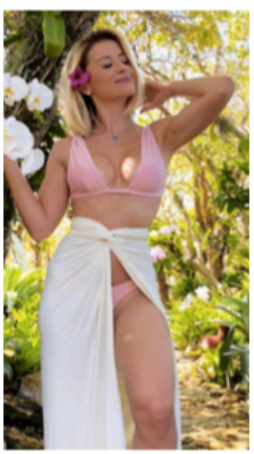

BÁRBARA FRANÇA

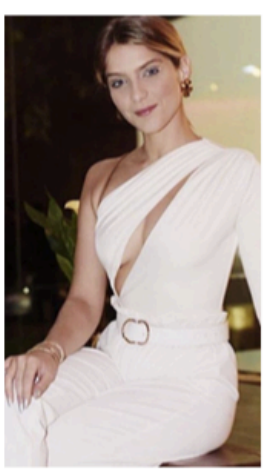

ISABELLA SANTONNI

\section{Figura 9: Inti Girls}

Fonte: Arquivos Inti (2019). 


\section{Etapas da Pesquisa}

Como ferramentas foram utilizadas pesquisas com os dados secundários e a análise de dados e entrevistas pessoais roteirizadas. As etapas da pesquisa estão relatadas a seguir.

\subsection{Etapa 1}

Inicialmente aconteceu uma conversa com as gestoras e criadoras da marca, Rebecca Lima e Giovanna Lorenzetti. Elas contaram detalhes sobre o conceito da marca e falaram sobre a importância do marketing digital no crescimento das vendas online, além de fornecerem informações sobre os objetivos de crescimento da Inti. Nesse momento, foi construído o tópico 1.1 da pesquisa, "A Inti", e criou-se base para as pesquisas relacionadas a contextualização do mercado que a empresa está inserida.

\subsection{Etapa 2}

A segunda etapa foi uma pesquisa sobre o mercado consumidor online, visando entender o comportamento do consumidor brasileiro na internet. Para isso, foram estudadas fontes secundárias, especificamente artigos acadêmicos e sites da internet com informações sobre o setor. Nesse momento, foi desenvolvido o segundo capítulo da pesquisa. O tópico 2.1 foi baseado em pesquisas sobre o mercado de moda, com mais atenção à moda praia. $O$ tópico 2.2 foi baseado no comportamento online dos brasileiros, o que deu mais base para o entendimento do problema a ser estudado na pesquisa.

\subsection{Etapa 3}

Nesta etapa do trabalho, foram entrevistadas 24 clientes da Inti que já compraram mais de uma vez no site da marca. As entrevistas foram relatadas no capítulo 4. O principal objetivo desta etapa era entender as características em comum entre essas clientes para criar o perfil das consumidoras do público alvo da empresa e compará-las com o perfil dos carrinhos abandonados. Além disso, buscou-se averiguar a relação das clientes com a marca, para medir o grau de atração e desejo que a marca gera nas consumidoras.

Contudo, ainda foram selecionadas mais 5 potenciais clientes que abandonaram carrinhos no site, visando recolher mais informações sobre o perfil das pessoas que se interessam pelos produtos a ponto de escolher as peças, mesmo sem comprá-las. 
Todas as entrevistadas receberam um cupom de $15 \%$ de desconto para ser usado em sua próxima compra.

\subsection{Etapa 4}

Após as entrevistas, foram selecionados 50 carrinhos abandonados e analisados sob a ótica do objetivo principal da pesquisa: entender a diferença entre as clientes que finalizam a compra e as que abandonam o carrinho. Os seguintes fatores foram considerados: valor, repetição de produtos ou variação de tamanhos dos mesmos adicionados ao carrinho e valor do frete.

\subsection{Etapa 5}

Buscando entender ainda melhor o público alvo da Inti, foi feita uma observação entre as vendas dos últimos 12 meses. 50 vendas foram analisadas para entender os carrinhos mais vendidos e compará-los com os carrinhos mais montados no site. Os mesmos critérios foram analisados: valor, repetição de produtos ou variação de tamanhos dos mesmos adicionados ao carrinho e valor do frete.

\subsection{Etapa 6}

Por fim, nesse momento, foi feito o confronto entre as informações recolhidas na pesquisa com as clientes e potenciais clientes, a análise dos carrinhos abandonados e a análise dos carrinhos mais vendidos pela marca. Com essas informações, foi feita a conclusão e elaboradas as recomendações à marca. 


\section{Entrevistas}

As entrevistas foram feitas via WhatsApp. Primeiramente, foram selecionadas 52 clientes que já haviam comprado mais de uma vez no site da marca. Foi feito um contato inicial com todas as selecionadas para verificar a disponibilidade das mesmas em responder as perguntas. Houve uma apresentação inicial da entrevistadora e do motivo da pesquisa, bem como do benefício de obter $15 \%$ de desconto em futuras compras, ao final do questionário.

A grande maioria das escolhidas se prontificou a responder as perguntas, mas nem todas as que iniciaram, terminaram a conversa. No final das entrevistas, 24 clientes haviam respondido todo o questionário.

Além disso, mais 5 pessoas que consecutivamente abandonaram carrinhos no site foram entrevistadas em uma segunda rodada de perguntas, visando entender se essas sabiam o que significava abandonar um carrinho em um e-commerce, suas razões para tal atitude, e o que as fariam mudar de ideia. A análise das entrevistas foi feita em três etapas: 1. Relação com a marca; 2. Características e Incentivos de consumo; 3. Abandono de Carrinhos. Todos os resultados foram relatados abaixo.

\subsection{Relação com a Marca}

A grande maioria das clientes conheceu a marca pelo Instagram, visto que a Inti tem mais de 55 mil seguidores. Esse foi um resultado esperado, e as respostas ajudaram a entender a qualificação das clientes vindas da rede. Em conversa com as gestoras, foi possível identificar a preocupação de trazer um público qualificado para o site, pois pelo fato de quase todo o investimento das campanhas serem em redes sociais, é necessário fazer uma constante verificação do público alvo atingido nos anúncios. Além do Instagram, foi possível analisar também que parte dessas clientes conheceram a marca por indicação de amigas, o que mostrou que a satisfação das clientes chega ao nível de recomendação da marca.

As clientes destacaram algumas características que dizem diferenciar a Inti de suas concorrentes, e definem a escolha na hora de comprar um produto como o oferecido pela empresa, as qualidades mais destacadas foram: sofisticação e diferenciação dos modelos, a elegância e versatilidade de usar as peças em diferentes ocasiões, e a qualidade dos produtos. Mariana Lima Barboza, de Sergipe destacou: "As peças são de muito bom gosto e 
a marca tem um estilo elegante e único que gosto muito!". Carol Castro, do Pará disse: "Peças clássicas atemporais e de qualidade".

Além disso, destacaram que o valor para os fretes "expressos" é atraente, principalmente para fora do Rio de Janeiro, mas ressaltam que gostariam de receber os pedidos mais rápido, pois muitas vezes compram para viajar ou para um evento específico.

Quando questionadas sobre quais tipos de produtos, moda praia ou roupas casuais, mais chamavam atenção na hora da compra, algumas respostas foram bastantes esclarecedoras, como é possível ver abaixo:

Quanto às roupas, o design e as peças diferentes chamam atenção das clientes, como no caso de Guinnerver de Melo, do Maranhão, que disse: "Os dois tipos me interessam bastante, mas acho que as peças de roupa na Inti são os diferenciais, porque biquínis em geral são mais fáceis de acharmos variedades, mas as roupas são de fato únicas".

Já quanto ao setor praia, elas opinaram que a versatilidade de transitar entre a praia e o pós-praia é a razão de comprar na Inti. Milena Paese, de Santa Catarina disse: "Praia com pegada para "pós-praia" é o que me encanta." e Danielly Alves de Paula, do Rio de Janeiro disse: "O que mais me atrai é o setor praia, por ser versátil e cair bem para um póspraia!".

Logo ao final das entrevistas, para finalizar o questionário, buscou-se uma resposta que concluísse a razão por essas pessoas gostarem da empresa e medir o quanto isso poderia influenciar no abandono de carrinhos pela vontade de comprar as peças associada à indecisão e ao valor dos produtos, visto que muitas disseram que deixam de finalizar uma compra pela dúvida do que comprar. As respostas mostraram como as clientes têm uma relação próxima e verdadeira com a marca: Daniela Saad, de São Paulo, quando questionada se pretende voltar a comprar na Inti disse: "Minha marca favorita. Sempre olho pra ver se chegou coisas novas. Até indiquei pra vocês terem uma pop-up store na NK de SP.", e por fim, a Camila Castro, do Pará: "Com toda certeza! Gostei das peças e achei o atendimento excelente com respostas rápidas e preocupação em agradar o cliente! Parabéns!".

\subsection{Características e Incentivos de Consumo}

A maioria das clientes alegou costumar comprar em lojas online, mas algumas pontuaram diferenciais interessantes, como as que afirmaram comprar roupas semanalmente em e-commerce, o que mostrou que, além de terem o poder aquisitivo alto, fazem parte do público alvo ideal para recorrência. Além disso, houve algumas respostas interessantes que ajudaram no entendimento dos abandonos dos carrinhos, como: "Amo comprar online, mas 
só após falar no WhatsApp com alguém da loja." e "Compro apenas de marcas que me recomendam.", sugerindo que o e-commerce ainda gera insegurança em muitos clientes que, por mais que se interessem e percorram os primeiros passos na trajetória da compra, desistem antes de concluir essa aquisição. Em adição, também houve algumas respostas relacionadas ao fato de só comprarem online quando este produto não existe em uma loja física, e essas explicaram que pesquisam na internet para ir ao shopping com certeza do que querem, e quando não encontram, voltam e realizam a compra online.

Os maiores motivos pelos quais as clientes defendem as compras online são a praticidade e a economia de tempo em relação a comprar em lojas físicas, associados a prazos de entrega curtos e fretes baratos ou gratuitos. Além disso, elas ressaltaram que sempre compram ao serem impulsionadas por descontos e facilidades de parcelamento. Houve quem destacasse que compra no site pois tem medo de que o produto acabe até chegar na loja física. Em adição, também houve quem dissesse que compra em sites que confia, pois isso assegura facilidade de troca ou devolução sem preocupações.

Em contrapartida, houve quem relatasse que o que mais impede a finalização de uma compra é o alto custo de frete, seguido da demora para entrega. Um outro fator que pesa bastante na decisão das clientes são problemas associados ao funcionamento do site, como lentidão, falta de segurança e requisição de muitos dados. Além disso, algumas disseram que só compram via boleto, e às vezes desistem da compra entre a emissão do boleto e o momento do pagamento, por constatarem, durante esse intervalo, que não precisam tanto dos produtos naquele momento.

\subsection{Abandono de Carrinhos}

Como o objetivo final era entender como as clientes encaravam o abandono de carrinhos e seus motivos de abandono, houve perguntas diretas e indiretas para analisar e medir esses fatores. $25 \%$ delas afirmaram que costumam abandonar carrinhos e navegar pelo site "por diversão", apenas para conhecer a coleção e comprar ou não em outro momento. Entre as entrevistadas, houve algumas respostas como "abandono às vezes" e "raramente, mas acontece" em relação ao abandono de carrinhos, mas no final, a grande maioria costuma abandoná-los pelo menos uma vez por semana. Algumas disseram que quando não finalizam a compra na hora, voltam em outro momento para realizar o pagamento no mesmo carrinho, o que não configura um abandono definitivo. Uma observação recorrente entre as clientes foi a de que costumam montar pedidos para fazer um orçamento, depois retiram alguns itens do carrinho e finalizam a compra.

As que afirmam abandonar o carrinho apresentaram justificativas interessantes: uma das clientes disse que costuma montar carrinhos e ir até o showroom da marca experimentar 
as peças. Outra disse que costuma montar carrinhos e entrar em contato pelo WhatsApp para finalizar a compra via depósito bancário.

Mais da metade das entrevistadas disseram que o valor do frete é o maior limitador da compra online, e o frete grátis as fariam mudar de ideia. Acompanhadas das respostas, algumas sugestões e observações interessantes surgiram por parte das clientes em relação a descontos posteriores ao abandono: "O desconto personalizado seria incrível, você ser tratada com uma cliente especial, motiva muito a retornar ao carrinho."; "Com certeza, ajuda muito! Compensa às vezes o valor do frete para clientes que moram mais longe" (depoimento de uma cliente que reside no estado de Minas Gerais); e "Sim, mas na verdade se recebesse cupons por ser cadastrada já ajudaria. Não precisaria ser só por deixar o carrinho"; "Sem dúvidas, pois o cancelamento normalmente é feito por causa do preço final".

Frente a isso, mais algumas clientes que haviam abandonado carrinhos mas não haviam comprado nos últimos meses, foram entrevistadas com uma abordagem mais direta sobre montar um pedido e não finalizar a compra, essas tiveram um comportamento peculiar, pois mesmo tendo iniciado o checkout e não finalizado, algumas, por mais de uma vez, insistiram que raramente abandonam um carrinho e que são muito decididas na hora de comprar online. No entanto, algumas respostas corroboraram com as respostas das clientes entrevistadas anteriormente: "Geralmente não, mas quando estou na dúvida das peças acabo deixando e voltando depois até me decidir". Além disso, também disseram que desistem da compra por medo das peças não servirem, ou por não acharem que precisam dos produtos naquele momento. $100 \%$ delas responderam que se fosse o caso de abandonar um carrinho, finalizariam a compra posteriormente caso ganhassem um cupom. 


\section{Análise dos Carrinhos}

Além das entrevistas, para complementar a análise dos carrinhos abandonados em relação aos finalizados, 50 carrinhos abandonados e 50 carrinhos finalizados foram analisados sob a ótica dos seguintes fatores: Valor, repetição e tamanho de produto adicionados ao carrinho e valor do frete.

\subsection{Carrinhos de Venda}

A análise dos carrinhos vendidos, ou seja, das vendas concluídas no site, resultou nas seguintes informações:

O ticket médio das vendas foi de $\mathrm{R} \$ 539,08$, com uma média de 1,67 itens por pedido. Além disso, as clientes, em sua maioria, são do estado de São Paulo (52\%). Destacaram-se também os estados no Norte e Nordeste, como Amazonas, Maranhão, Paraíba e Maceió, que mesmo com fretes acima da média, chegando a $\mathrm{R} \$ 62,00$ para a cidade de Manaus, representaram $14 \%$ das vendas. Para outros estados como Goiás, Paraná, Santa Catarina, Minas Gerais e Mato Grosso, houve vendas, mas nenhum estado se destacou, e os fretes seguiram a média, que foi de $\mathrm{R} \$ 26,00$ por pedido. Em adição, as clientes aguardaram em média 6 dias para a entrega dos pedidos.

Outro dado relevante na análise foi que $23 \%$ dos pedidos foram feitos com produtos tamanho G, $37 \%$ de tamanho $P$ e $40 \%$ tamanho $\mathrm{M}$.

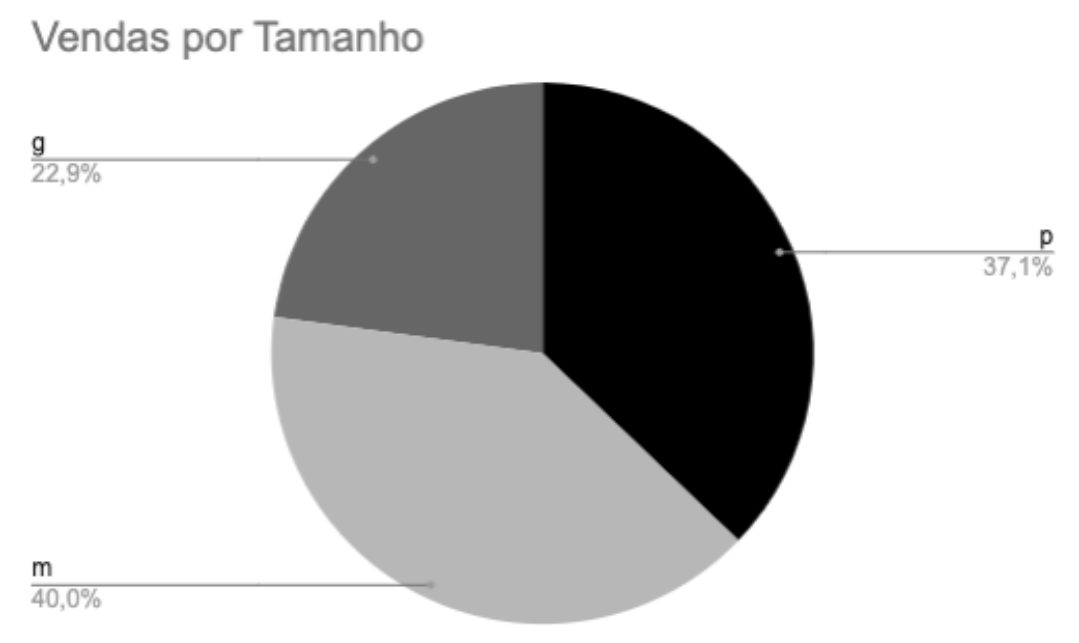

Figura 10: Vendas por Tamanho em intiswim.com

Fonte: Elaborada pela autora. 


\subsection{Carrinhos Abandonados}

Durante a análise dos carrinhos abandonados, as seguintes observações foram feitas e relatadas: $82 \%$ dos carrinhos abandonados eram do sudeste, em especial, $75 \%$ do Rio de Janeiro e São Paulo, onde o frete varia entre $R \$ 9,73$ e $R \$ 21,24$ pela transportadora mais barata, a Flash Courier, para o peso dos produtos enviados. Além do valor da transportadora, a Inti adiciona uma taxa de $R \$ 1,00$ ao frete, referente a custos de embalagem.

Tabela 1: Tabela de Fretes Flash Courier

\begin{tabular}{|l|l|l|}
\hline Peso $(\mathrm{kg})$ & $\mathrm{RJ}-\mathrm{RJ}$ & $\mathrm{RJ}-\mathrm{SP}, \mathrm{ES}, \mathrm{MG}$ e PR \\
\hline 0 a $300 \mathrm{~g}$ & $\mathrm{R} \$ 9,73-\mathrm{R} \$ 14,03$ & $\mathrm{R} \$ 20,50$ \\
\hline 300g a $500 \mathrm{~g}$ & $\mathrm{R} \$ 10,44-\mathrm{R} \$ 15,56$ & $\mathrm{R} \$ 20,50$ \\
\hline $500 \mathrm{~g}$ a $1 \mathrm{~kg}$ & $\mathrm{R} \$ 11,18-\mathrm{R} \$ 16,52$ & $\mathrm{R} \$ 21,24$ \\
\hline
\end{tabular}

Fonte: Contrato comercial de transporte Inti x Flash.

Além disso, todos os carrinhos abandonados tinham peças nos tamanhos $\mathrm{P}(62 \%) \mathrm{e}$ M (38\%), nenhum tamanho $\mathrm{G}$, o que difere bastante da realidade das vendas. O ticket médio desses carrinhos era de $\mathrm{R} \$ 551,94$, com uma média de 1,75 peças por pedido, próximo ao ticket médio real da empresa. 


\section{Recomendações}

Após a conversa com as clientes e a análise dos carrinhos, alguns comportamentos foram relatados para que sugestões fossem dadas a empresa, visando a redução do número de abandono de carrinhos e a conversão desses abandonos em vendas.

\subsection{Relacionamento com as Clientes}

A recomendação do site por conhecidos e a percepção de que há confiança entre as clientes e a marca, é um grande incentivo para as compras, principalmente no meio online. Segundo Prochnow (2019), ter as necessidades atendidas é a forma mais eficaz de gerar fãs da marca, conectando os clientes, para que esses validem e promovam a qualidade do serviço e dos produtos da empresa, humanizando o que pode vir a desencorajar o comércio virtual, que, por mais que já esteja solidificado na cultura de consumo, e seja crescente no Brasil, ainda causa estranhamento e receio a clientes de perfil mais tradicional.

Ainda sobre relacionamento, a exploração das explicações e ilustrações dos diferenciais da marca, como a modelagem, design e exclusividade das peças, pode ser um gatilho que incentive a finalização das compras por canais alternativos como o WhatsApp. Como foi relatado pelas clientes, o atendimento personalizado que contemple e desperte ainda mais o desejo pelas peças e a escassez dos produtos, as fariam mudar de ideia quando abandonam um carrinho. Esse serviço, pode ser associado a uma política de desconto recorrente para as clientes fiéis da marca, visto que algumas fazem compras mensais acima de $R \$ 1000,00$ no site e relataram que o atendimento especial as fariam considerar ainda mais o consumo dos produtos da Inti.

Um outro ponto a ser abordado, é que não há carrinhos abandonados no tamanho G, porém esses representam 22,9\% das vendas. Quanto a isso, notou-se entre as clientes que há um certo receio das peças não servirem, mas essas sabem que há a possibilidade de trocar ou devolver os produtos sem grandes preocupações. Reforçar a tabela de medidas, usabilidade e a facilidade de contato e troca, pode incentivar a compra e o interesse de um público potencial que vá ver com mais atenção as peças, e explorarem mais a marca sem receio. 


\subsection{Ferramentas no Site}

Além disso, algumas ferramentas que foram relatadas como diferenciais na decisão de compra também podem ser implementadas no site. A primeira delas é uma seção de comentários, para reforçar a prova social da empresa frente à satisfação das suas clientes. Segundo Adolpho (2012), quanto mais depoimentos e comentários, mais credibilidade o site passa aos novos visitantes, pois o ser humano busca uma sensação de pertencimento, e as provas sociais conferem isso a elas. Todo o feedback que foi recebido pelo WhatsApp durante as entrevistas mostrou como as clientes são solícitas a conversas via chat e dispostas a participarem mais intimamente do processo de compra e, consequentemente, dar feedbacks sobre as peças, o que, quando exposto em uma seção de comentários, pode gerar mais confiança entre as novas compradoras ou visitantes que ainda não têm intenção de compra.

Um outro ponto levantado pelas clientes como limitador nas compras é a facilidade de pagamento via depósito bancário. Notou-se que é um hábito e um desejo das clientes da marca quererem comprar os produtos conversando com uma atendente, pois pedem opiniões sobre as peças, mas também por poder fazer a finalização da compra via depósito, o que facilita a confiança no recebimento e não envolve cartão de crédito. Sendo assim, este mecanismo implementado no site também pode vir a incentivar a finalização de compra e reduzir o número de carrinhos abandonados. Neste caso, as peças também já estariam reservadas para a clientes, assim como é feito via boleto, validando novamente o posicionamento de algumas clientes que têm medo da peça acabar, e também das que visam a praticidade acima de tudo.

\subsection{Frete}

Por fim, de todos os relatos, o ponto mais comentado pelas clientes e também observado na análise dos carrinhos foi o valor do frete e do prazo de entrega. A Inti tem espaço para ter um frete mais competitivo em relação aos concorrentes, em valor e prazo de entrega. A Esc Brand, oferece entrega expressa de até 1 dia útil tanto para o Rio de Janeiro $(R \$ 9,00)$, quanto para São Paulo $(R \$ 25,00)$, onde a Inti tem seu maior público concentrado. Já a Haight, oferece frete grátis via PAC para todas as compras, independentemente do valor e também consegue entregar no Rio de Janeiro de 1 a 2 dias úteis.

A oportunidade neste seguimento de frete "expresso" é grande, visto que que os produtos são semelhantes, com valores próximos, e muitas clientes tem pressa na compra, pois querem os itens para festas e viagens já próximos a data do pedido. 
Segue abaixo uma comparação do valor e prazo de entrega na modalidade PAC da Inti e da Haight para o mesmo endereço, no Rio de Janeiro e em seguida em São Paulo. CEP usado para fins demonstrativos para frete no Rio de Janeiro: 22793-084 (Barra da Tijuca). CEP usado para fins demonstrativos para frete em São Paulo: 01452-001 (Jardim Paulistano).

Tabela 2: Comparação Frete Rio de Janeiro

\begin{tabular}{|l|l|l|}
\hline Frete RJ Inti $x$ Haight & Valor & Prazo \\
\hline Inti & $\mathrm{R} \$ 13,30$ & até 7 dias úteis \\
\hline Haight & Grátis & 1 a 2 dias úteis \\
\hline
\end{tabular}

Fonte: Elaborado pela autora.

Tabela 3: Comparação Frete São Paulo

\begin{tabular}{|l|l|l|}
\hline Frete SP Inti $x$ Haight & Valor & Prazo \\
\hline Inti & $\mathrm{R} \$ 22,22$ & até 7 dias úteis \\
\hline Haight & Grátis & 6 a 7 dias úteis \\
\hline
\end{tabular}

Fonte: Elaborado pela autora.

Com base nas tabelas acima, fica evidente que na comparação entre envios dentro do Rio de Janeiro, a Haight vence em valor e prazo de entrega, e para São Paulo, vence em valor e empata em prazo de entrega. Sendo assim, entre clientes que não conhecem as marcas e estão em busca dos produtos semelhantes que ambas oferecem, frente a uma compra urgente, é possível que a cliente opte por comprar um produto Haight.

Segundo Patel (2019), estratégias de frete grátis tiveram impacto de $50 \%$ a $90 \%$ no aumento da conversão em sites de diversos setores entre o público feminino, como por exemplo a NuFACE, marca de cosméticos femininos que atua nos EUA e no Canadá. Isso porque o frete é o que diferencia o valor de uma compra online versus a compra em loja física, pois os consumidores desconsideram os custos da ida a loja, como gastos com combustível ou estacionamento, por exemplo. Sendo assim, o custo de frete é o ponto de maior preocupação entre as clientes, e mostrou-se o maior gargalo impedidor de vendas entre as consumidoras entrevistadas. 


\subsection{Recomendações Finais}

Sendo assim uma estratégia de frete grátis acompanhada de atendimento personalizado via WhatsApp com descontos sobre o valor do carrinho e incentivo a recorrência de compra, traz as clientes para mais perto da marca, e as torna não só consumidoras, mas também, representantes dos produtos. Segundo Solomon (2011), o papel do marketing é reconhecer o que ajuda o consumidor a decidir por quais produtos ele se sente mais atraído e quais deles se destacam entre os concorrentes ofertados no mercado. Portanto, estar ciente das ações dos concorrentes e dos desejos das consumidoras, são as principais formas de manter o público fiel e fazer com que esses escolham a Inti quando há dúvida na hora da compra.

A atenção aos detalhes que diferenciam a Inti da concorrência e ouvir o que as clientes têm a dizer, mostra as mesmas que suas necessidades e desejos são considerados importantes e permite que a marca esteja sempre se atualizando e surpreendendo seu público. Para Kotler e Keller (2006), entender o cliente a fundo ajuda a assegurar que os produtos certos estão sendo comercializados para o público certo, pelo canal certo. 


\section{Conclusão e Considerações Finais}

O presente trabalho se iniciou com o objetivo de investigar as razões do alto número de carrinhos abandonados no E-commerce da Inti. Para iniciar a pesquisa, houve uma conversa com as gestoras para explicação dos objetivos do trabalho e um estudo sobre o cenário que a empresa está inserida. Em seguida, fez-se um levantamento dos hábitos de compra e maiores gargalos da venda online. Posteriormente, foi feita uma pesquisa qualitativa com as clientes da marca e ainda, uma análise dos carrinhos abandonados e finalizados no site da marca.

Pode-se concluir que as clientes da marca são muito fiéis e interessadas em todos os produtos lançados, há uma expectativa grande e essas são potenciais fãs promotoras do negócio. Pelo interesse e paciência das clientes durante as entrevistas, verificou-se que há um grande espaço para conhecer melhor o público, que além de interesse em compras, também incentiva e recomenda melhorias para a marca.

As principais recomendações dadas à empresa foram relacionadas ao impacto do frete na conversão dos carrinhos, e também do atendimento posterior ao abandono, visto que todas as clientes e potenciais clientes estavam dispostas a receber um atendimento personalizado e muito interessadas em descontos para conversão dos carrinhos abandonados e até mesmo pela fidelidade à marca. Também foram sugeridas algumas alterações no site que podem ajudar a validar a autoridade e segurança da marca, como uma seção de comentários e a possibilidade de vender via depósito.

Vale destacar que a partir do mês de outubro, a estratégia de frete grátis para compras acima de $\mathrm{R} \$ 500,00$ começou a ser praticada. Como recomendação, seria interessante medir o impacto desta ação nas vendas por estado e também consultar as clientes para entender se esse benefício foi um decisor para a finalização do pedido ou até mesmo para um upgrade da compra visando atingir a cota de $\mathrm{R} \$ 500,00$ e receberem o frete grátis.

Por fim, em outubro também se iniciou uma campanha via Instagram Ads, que direciona o público para o WhatsApp da loja, onde as clientes tiram dúvidas e recebem orientações sobre os produtos, nas primeiras 3 semanas de funcionamento da mesma, $12,48 \%$ das vendas vieram de clientes oriundas desta campanha específica.

Para estudos futuros, recomenda-se uma análise técnica do site para potenciais melhorias em UX e UI, visto que este é um diferencial da concorrência e que o público se mostrou tendencioso a estímulos visuais e preocupado com o bom funcionamento da área de checkout. 


\section{Referências Bibliográficas}

ADOLPHO. C. Como utilizar os elementos de persuasão de Prova social e Autoridade. 2002. Disponível em: <https://www.conrado.com.br/prova-social-e-autoridade/> Acesso em 5 de outubro de 2019.

DUCOFFE, R. H. Advertising value and advertising the Web. Journal of Advertising Research, v. 36, n. 5, p. 21-35, 1996.

GOH, K.-Y.; HENG, C.-S.; LIN, Z. Social Media Brand Community and Consumer Behavior: Quantifying the Relative Impact of User- and Marketer- Generated Content. Information Systems Research, v. 24, n. 1, p. 88-107, 2013.

JOHNSON, J. P. Targeted advertising and advertising avoidance. RAND Journal of Economics, v. 44, n. 1, p. 128-144, 2013.

JÚNIOR. C. E-commerce feminino: um mercado cada vez mais promissor. Ecommerce Brasil. Disponível em: <https://www.ecommercebrasil.com.br/artigos/mercadofeminino-na-internet/> Acesso em 15 de setembro de 2019.

KOTLER, Philip. Administração de marketing: análise, planejamento, implementação e controle. 5. ed. São Paulo: Atlas, 1998.

KOTLER, Philip; KELLER, Kevin Lane. Administração de marketing. 12. ed. São Paulo: Pearson Prentice Hall, 2006.

LIMA, R. LORENZETTI. G. Entrevista concedida a Elizabete Menezes. Rio de Janeiro, 10 de setembro de 2019.

MANGOLD, W. G.; FAULDS, D. J. Social media: The new hybrid element of the promotion mix. Business Horizons, v. 52, n. 4, p. 357-365, 2009.

MISSIADIA. M. Quase 70\% dos carrinhos de eletroeletrônicos são abandonados. Diário de Comércio. Disponível em: <https://dcomercio.com.br/categoria/negocios/quase-70dos-carrinhos-de-eletroeletronicos-sao-abandonados> Acesso em 09 de outubro de 2019.

MONTEIRO, N. A. B. C. As motivações para a compra online: Comportamento de compra do consumidor digital. Porto - 2018. Dissertação (Mestrado em Marketing Digital) - Instituto Superior de Contabilidade e Administração do Porto.

NEOATLAS: E-commerce Radar $1^{\circ}$ Semestre de 2018. Disponível em: < https://s3sa-east-1.amazonaws.com/s3.neomove.com.br/E-book-Neoatlas-Geral-1SEM-2018.pdf> Acesso em: 11 de outubro de 2019.

OLIVEIRA. B. Como diminuir o abandono do carrinho de compras no seu ecommerce? 28 novembro 2017.2 Disponível $<$ https://administradores.com.br/noticias/como-diminuir-o-abandono-do-carrinho-decompras-no-seu-e-commerce> Acesso em: 27 de setembro de 2019.

OZCELIK, A. B.; VARNALI, K. Effectiveness of online behavioral targeting: A psychological perspective. Electronic Commerce Research and Applications, v. 33, 2019. 
PATEL. N. How to Make "Free Shipping" Profitable. Disponível em: $<$ https://neilpatel.com/blog/make-free-shipping-profitable/> Acesso em 12 de outubro de 2019.

PROCHNOW. C. Como transformar clientes em promotores: tenha fãs da sua marca. Disponível em: <https://rockcontent.com/blog/como-transformar-clientes-empromotores/> Acesso em: 20 de outubro de 2019.

SCHLOSSER, A. E.; SHAVITT, S.; KANFER, A. Survey of Internet users' attitudes toward Internet advertising. Journal of Interactive Marketing, v. 13, n. 3, p. 34-54, 1999.

SOLOMON, M. R. O comportamento do consumidor: comprando, possuindo e sendo. 9a edição. Porto Alegre: Bookman, 2011.

STATISTA: Primary reason for digital shoppers in the United States to abandon
their $\quad$ carts as of November 2018. Disponivel em: $<$ https://www.statista.com/statistics/379508/primary-reason-for-digital-shoppers-to-abandoncarts/> Acesso em 18 de setembro de 2019.

TONI. G. Mercado de moda deve crescer $3,1 \%$ ao ano até 2021. Agência Indusnet Fiesp. Disponível em: <https://www.fiesp.com.br/noticias/mercado-de-moda-deve-crescer31-ao-ano-ate-2021/> Acesso em: 20 de outubro de 2019.

VASCONCELOS, M. B. F. Fatores que influenciam a intenção de compra através de anúncios em mídias sociais. Rio de Janeiro - 2019. Dissertação de mestrado em Administração de Empresas da PUC- Rio.

WE ARE SOCIAL. Global Internet Use Accelerates. We Are Social, 30 jan. 2019. Disponível em: <https://wearesocial.com/us/blog/2019/01/digital-2019-global-internet-useaccelerates> Acesso em: 23 de setembro de 2019.

ZAMPIERI. T. Frete! $O$ pesadelo de todo gestor de e-commerce. E-commerce Brasil. 07 de fevereiro de 2014.2 Disponível em: $<$ https://www.ecommercebrasil.com.br/artigos/frete-o-pesadelo-de-todo-gestor-de-ecommerce/> Acesso em: 12 de setembro de 2019. 


\section{Anexo 1}

Pesquisa qualitativa com clientes ativas da Inti. Monografia de Elizabete Menezes.

Roteiro para entrevistas:

1. Como conheceu a marca?

2. Qual o seu maior incentivo em comprar uma peça da Inti?

3. Se interessa mais pelas roupas ou pelo setor praia?

4. Costuma comprar em lojas online com frequência?

5. Quais motivos te incentiva mais a finalizar uma compra online?

6. Quais motivos te fazem deixar de finalizar uma compra online?

7. Você costuma abandonar carrinhos em sites de venda?

8. Você costuma abandonar carrinhos no site da Inti?

9. Te motivaria a comprar se recebesse um desconto para finalizar sua compra que foi abandonada em um carrinho recentemente?

10. Receber um atendimento prioritário via WhatsApp para tirar dúvidas e apresentar detalhes das peças te faria considerar mais a marca?

11. Compraria novamente na Inti? 


\section{Anexo 2}

Pesquisa qualitativa com potenciais clientes que abandonaram carrinhos no site da Inti. Monografia de Elizabete Menezes.

Roteiro para entrevistas:

1. Costuma comprar em lojas online com frequência?

2. Quais motivos te incentiva mais a finalizar uma compra online?

3. Você costuma abandonar carrinhos em sites de venda e não finalizar a compra?

4. Quais motivos te fazem desistir de finalizar uma compra online?

5. Te motivaria a comprar se recebesse um desconto para finalizar sua compra que foi abandonada em um carrinho recentemente?

6. Receber um atendimento prioritário via WhatsApp para tirar dúvidas e apresentar detalhes das peças te faria considerar mais a marca? 